\title{
Effect of glucose on fermentation heat in sheep rumen fluid in vitro
}

\author{
BY A. ARIELI \\ The Hebrew University of Jerusalem, Faculty of Agriculture, PO Box 12, \\ Rehovot 76-100, Israel
}

(Received 8 January 1986 - Accepted 14 March 1986)

1. Heat production rate $(H)$ of rumen fluid was measured in a direct calorimeter. Basal $H$ of samples of $15 \mathrm{ml}$ rumen fluid mixed with $45 \mathrm{ml}$ buffer was $0.4 \mathrm{~mW} / \mathrm{ml}$ rumen fluid.

2. Addition of glucose $(0.46 .4 \mathrm{mg} /$ sample) was followed by a dose-dependent increase in $\dot{H}$. Maximal $\dot{H}$ was $1.1 \mathrm{~mW} / \mathrm{ml}$ and lasted up to $5 \mathrm{~min}$, returning thereafter to the basal level.

3. Expression of fermentation heat $\left(H_{\mathrm{f}} ; \mathrm{kJ} / \mathrm{mol}\right.$ substrate added) against glucose dose indicated an asymptotic dose response.

4. Maximal $H_{\mathrm{f}}$ (at infinite dilution) agreed with stoichiometric calculations whereas minimal $H_{\mathrm{f}}$ suggested a partial fermentation of the substrate at a high-glucose dose in the rumen environment.

Carbohydrates are fermented within the anaerobic environment of the rumen, giving rise mainly to volatile fatty acids (VFA), methane, $\mathrm{CO}_{2}$, water, heat and microbial matter. According to stoichiometric calculations the fermentation heat $\left(H_{\mathrm{f}}\right)$ is $180 \mathrm{~kJ} / \mathrm{mol}$ when hexoses are fermented in the rumen. This value is almost constant, regardless of the proportions of the end-products (Hungate, 1966). However, experimental determinations of $H_{\mathrm{f}}$ vary from $140 \mathrm{~kJ} / \mathrm{mol}$ (Hershberger \& Hartstook, 1970) to $360 \mathrm{~kJ} / \mathrm{mol}$ (Menke \& Ehresvard, 1974).

The large variation in experimental results may be related to the determination procedure. $H_{\mathrm{f}}$ was measured indirectly by difference from carbon balance of in vitro fermentation (Marston, 1948; Menke \& Ehresvard, 1974), or estimated from the difference between total visceral metabolism and the aerobic metabolism of the tissues of the gut wall (Webster et al. 1975). Some of the direct determinations of $H_{\mathrm{f}}$ in rumen contents are within the range of stoichiometrically calculated values (Houpt, 1968; Hershberger \& Hartstook, 1970). In these latter studies $H_{\mathrm{f}}$ was measured over relatively long periods of several hours over which microbial mass could vary and thereby affect $H_{\mathrm{f}}$.

Information on $H_{\mathrm{f}}$ of rumen micro-organisms over short periods is not available. Discrepancies between rumen $H_{\mathrm{f}}$ values from expected stoichiometric calculations may also be explained by the direct incorporation of substrates into cell microbial matter (Forrest, 1969, Seeley et al. 1969), which is influenced by energy availability (Bauchop \& Elsden, 1960 ). Hence, it might be assumed that with low inputs of substrate the proportion of substrate energy converted to heat is relatively high, whereas these proportions decrease when substrate is rechannelled from fermentation to polysaccharide formation. Such a hypothesis was examined in the present study by assessing the effect of glucose dose on rumen $H_{\mathrm{f}}$ over short periods.

MATERIALS AND METHODS

Prefeed samples of rumen fluid were removed from sheep fed on a hay - concentrate diet $(1: 2 \mathrm{w} / \mathrm{w})$ by suction via a stomach tube. Samples were transferred to the laboratory in a prewarmed vacuum flask and bubbled with carbon dioxide. Ingesta were homogenzied for six periods of $10 \mathrm{~s}$ over 2 min to dislodge some of the micro-organisms from feed particles. The homogenized ingesta were strained to yield the inocula. 
Strained fluid samples were transfered to $100 \mathrm{ml}$ flasks, mixed with McDougall (1948) artificial saliva and flushed with $\mathrm{CO}_{2}$. The extent of dilution of ruminal fluid with buffer is given below. Flasks were plugged with Bunsen stoppers and incubated in a thermostatic water-bath at $39 \cdot 2^{\circ}$ for at least $2 \mathrm{~h}$ for stabilization. Typical $\mathrm{pH}$ values of mixed rumen fluid samples were within the range $6 \cdot 7-6 \cdot 9$; they decreased towards the end of incubation by $0 \cdot 1-0 \cdot 2$ units.

Heat production $(\dot{H})$ was measured in a semiadiabatic titration calorimeter (model 450 ; Tronac, Orem, Utah). The calorimeter was equipped with a $100 \mathrm{ml}$ rapid-response silvered-glass Dewar reaction vessel. The Dewar assembly comprises stirrer, heater, thermistor and titrant tubes. The heater facilitated an electrial calibration and enabled the setting of temperature to the desired level. The heat change and the rate of heat flow was calculated from changes in the temperature of a medium with a known heat capacity with the thermistor output recorded. The medium was stirred by a glass stirrer at $600 \mathrm{rev} / \mathrm{min}$.

Continuous thermograms with a precision of $40 \mathrm{~mJ}$, were recorded using a Yokogava recorder (Model 3407) with a sensitivity of $0.5-1 \mathrm{mV}$ full-scale deflection range and a chart speed of $10-20 \mathrm{~mm} / \mathrm{min}$. The calorimeter-bath temperature was set at $39 \cdot 0^{\circ}$.

Electrical calibration was performed by filling the reaction vessel with $60 \mathrm{ml}$ water and measuring the stirrer (blank) effect $v$. the heat evolved by a 100 (SE 0.01 ) ohm resistor set to produce $21.7 \mathrm{~mJ} / \mathrm{s}$. Calibration was performed at least twice a day resulting in a mean calibration factor of $1 \mathrm{uV}=11 \cdot 7 \mathrm{~mJ}$ (SE $0 \cdot 12$ ).

The $H$ in rumen fluid samples was calculated with the aid of the recorder trace. The heat produced by a subsequent reaction above the steady-state reading (as the heat evolved due to addition of substrate) was determined as the difference between the extrapolated lines relating the quantity of heat produced to time (see Fig. 1).

Samples were rapidly introduced into the reaction vessel under a stream of $\mathrm{CO}_{2}$ and inserted into the calorimeter bath. Thermal perturbation decayed within minutes. Due to the similarity of the water-bath and calorimeter temperatures and to rapid transition of samples, only minor heating $(20-80 \mathrm{~mJ} / \mathrm{s}$ for a few minutes) of the reaction vessel contents was needed in order to bring them up to set temperature.

After reaching a steady rate of $\dot{H}$, a single dose of glucose was added to the reaction vessel. The glucose solution was prewarmed in the calorimeter bath in a burette and transferred to the reaction vessel at a rate of $0.4 \mathrm{ml} / \mathrm{min}$ (SE $0.1 \%$ ). The calorimetric measurement was terminated after $\dot{H}$ returned to basal values. A typical single run lasted for about $30 \mathrm{~min}$.

Three experiments were performed to determine the effect of glucose addition on $\dot{H}$ of rumen fluid in vitro.

Expt 1. The effect of dilution of rumen fluid with buffer on basal $\dot{H}$ and $H_{\mathrm{f}}$ of glucose was studied using three dilutions ( $\mathrm{ml}$ rumen fluid: $\mathrm{ml}$ buffer; $10: 5015: 45$ and $20: 40$ ) together with single glucose doses $(\mathrm{mg} ; 1 \cdot 6,3 \cdot 2$ and 6.4). Subsequent experiments were conducted with a dilution of $15 \mathrm{ml}$ rumen fluid: $45 \mathrm{ml}$ buffer.

Expt 2 . The effect of the duration of glucose infusion on $\dot{H}$ was studied using single doses of glucose; $1.6 \mathrm{mg} / \mathrm{min}$ were infused into $15 \mathrm{ml}$ rumen fluid plus $45 \mathrm{ml}$ buffer for 1,2 or 4 min but 1 min infusion of glucose was used in the subsequent experiment.

Expt 3. The final experiment in the series was designed to study the effects of glucose dose on $H_{\mathrm{f}}$ and on $\dot{H}$ in rumen fluid. This experiment was designed to reduce variation between inocula. On each experimental day measurements of $\dot{H}$ were made in fifteen rumen fluid samples (five doses times three determinations). Thus $7 \mathrm{~h}$ lapsed between the first and last determination from the same inoculum. The mean $\dot{H}$ by rumen fluid samples was not significantly affected by the period of incubation in the water-bath. 


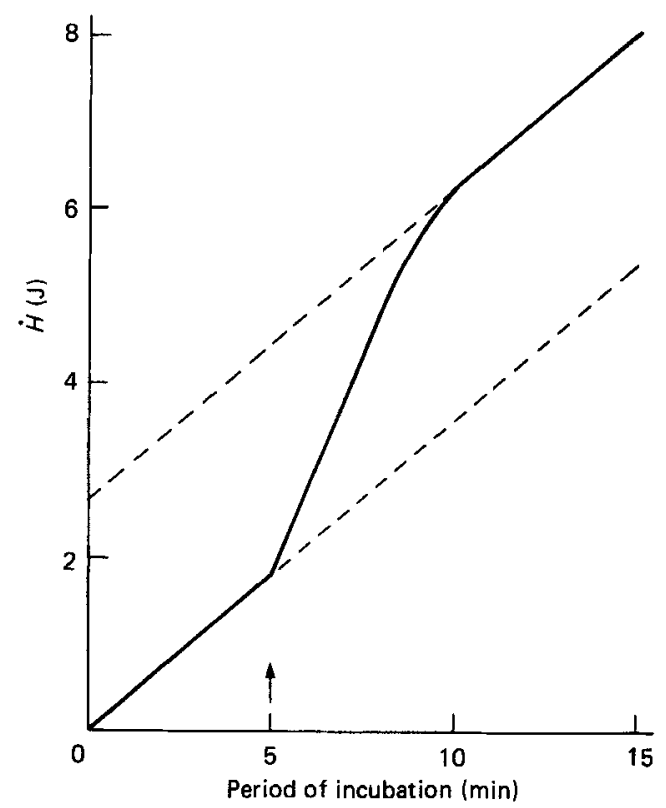

Fig. 1. Effect of a single glucose dose $(6.4 \mathrm{mg})$ on heat production rate $(\mathrm{J} ; H)$ in rumen samples $(15 \mathrm{ml}$ rumen fluid plus $45 \mathrm{ml}$ buffer). $\uparrow$, Time of administration.

\section{Calculations}

Results for $\dot{H}$ were expressed as $\mathrm{mW} / \mathrm{ml}$ rumen fluid and $H_{\mathrm{f}}$ as $\mathrm{kJ}$ dissipated as heat $/ \mathrm{mol}$ substrate added. Results are given as means with their standard errors; comparisons between treatments were analysed by Student's $t$ test and analysis of variance. An asymptotic curve of the form $y=\mathrm{a}+\mathrm{b} \cdot \mathrm{e}^{\mathrm{e} x}$ was fitted to the values from Expt 3, where $x$ is glucose dose $(\mathrm{mg}), y$ is $H_{\mathrm{f}}$ and a, b and $\mathrm{c}$ are constants. Values of these parameters were solved by an iteration procedure based on Newton's approximation.

\section{RESULTS}

When a rumen fluid inoculum was incubated without exogenous substrate, a minimal $\dot{H}$ was observed. $\dot{H}$ of rumen micro-organisms was stable for several hours, having a mean coefficient of variation of $12 \%$.

Fig. 1 depicts a typical incubation, $1.80 \mathrm{~J}$ were dissipated by $15 \mathrm{ml}$ rumen fluid and $45 \mathrm{ml}$ buffer, during $5 \mathrm{~min}$ before glucose infusion. This is indicated by the basic slope which is equivalent to a value for $\dot{H}$ of $0.36 \mathrm{~mW} / \mathrm{ml}$ rumen fluid. When $6.4 \mathrm{mg}$ glucose was added (during a $1 \mathrm{~min}$ infusion), $\dot{H}$ increased immediately, the steeper slope demonstrates an increase to $1.05 \mathrm{~mW} / \mathrm{ml}$ rumen fluid. Thereafter $\dot{H}$ declined and $5 \mathrm{~min}$ after the introduction of the substrate, the value for $\dot{H}$ was similar to the basal value. The difference between the two parallel lines represents $H_{\mathrm{f}}$ which in Fig. 1 is $75 \mathrm{~kJ} / \mathrm{mol}$.

\section{Expt 1}

An increase in rumen fluid concentration in the reaction vessel was associated with a decrease in basal $\dot{H}$ from $0.52 \mathrm{~mW} / \mathrm{ml}$ rumen fluid at a dilution of 1.5 to $0.31 \mathrm{~mW} / \mathrm{ml}$ rumen fluid at a dilution of $1: 2(P<0 \cdot 001$; Table 1$)$.

Increases in rumen fluid concentration were usually followed by increases in stimulated 
Table 1. Expt 1. Effect of dilution with buffer on basal rate of heat production $(\dot{\mathrm{H}})$ and on glucose induced fermentation heat $\left(\mathrm{H}_{f}\right)$ in rumen fluid

(Mean values with their standard errors; no. of determinations in parentheses)

\begin{tabular}{|c|c|c|c|c|c|c|c|c|}
\hline \multirow{3}{*}{$\begin{array}{l}\text { Rumen } \\
\text { fluid:buffer }(\mathrm{ml}: \mathrm{ml})\end{array}$} & \multirow{2}{*}{\multicolumn{2}{|c|}{$\begin{array}{l}H(18)(\mathrm{mW} / \mathrm{ml} \\
\text { rumen fluid) }\end{array}$}} & \multicolumn{6}{|c|}{$H_{\mathrm{f}}(6)(\mathrm{kJ} / \mathrm{mol})$} \\
\hline & & & \multicolumn{2}{|c|}{$1.6^{*}$} & \multicolumn{2}{|c|}{$3 \cdot 2^{*}$} & \multicolumn{2}{|c|}{$6 \cdot 4^{*}$} \\
\hline & Mean & SE & Mean & $\mathrm{SE}$ & Mean & $\mathrm{SE}$ & Mean & SE \\
\hline $10: 50$ & $0 \cdot 52^{a}$ & 0.01 & 120 & 8 & 102 & 6 & $74^{\mathrm{a}}$ & 3 \\
\hline $15: 45$ & $0.39^{b}$ & 0.01 & 108 & 6 & 82 & 5 & $72^{\mathrm{a}}$ & 2 \\
\hline $20: 40$ & $0.31^{\mathrm{c}}$ & 0.01 & 117 & 6 & 88 & 2 & $63^{\mathrm{b}}$ & 1 \\
\hline
\end{tabular}

w, b, c Mean values with different superscript letters differed significantly $(P<0 \cdot 05)$.

* Glucose $(\mathrm{mg})$ added to the reaction vessel.

Table 2. Expt 2. Effect of duration of glucose infusion on rate of heat production $(\dot{\mathrm{H}})$ and on fermentation heat $\left(\mathrm{H}_{f}\right)$ in rumen fuid

(Mean values with their standard errors for six determinations)

\begin{tabular}{|c|c|c|c|c|c|}
\hline \multirow{2}{*}{$\begin{array}{l}\text { Duration of } \\
\text { infusion } \dagger \text { (min) }\end{array}$} & \multirow{2}{*}{$\begin{array}{l}\text { Amount } \\
\text { of glucose } \\
\text { infused } \\
\text { (mg) }\end{array}$} & \multicolumn{2}{|c|}{$\begin{array}{c}\dot{H} \\
(\mathrm{~mW} / \mathrm{ml} \text { rumen fluid) }\end{array}$} & \multicolumn{2}{|c|}{$\begin{array}{c}H_{\mathrm{f}} \\
(\mathrm{kJ} / \mathrm{mol})\end{array}$} \\
\hline & & Mean & $\mathrm{SE}$ & Mean & $\mathrm{SE}$ \\
\hline 1 & $1 \cdot 6$ & 0.78 & 0.01 & $111^{\mathrm{a}}$ & 1 \\
\hline 2 & $3 \cdot 2$ & 0.74 & 0.01 & $94^{\mathrm{b}}$ & 1 \\
\hline 4 & 6.4 & 0.82 & 0.01 & $86^{\mathrm{e}}$ & 2 \\
\hline
\end{tabular}

a, b, c Mean values with different superscript letters differed significantly $(P<0 \cdot 05)$.

† Glucose infused at $1.6 \mathrm{mg} / \mathrm{min}$.

$\dot{H}$ and by a faster return of $\dot{H}$ to basal values (not shown). Dilution had no consistent effect on $H_{\mathrm{f}}$ when 1.6 or $3.2 \mathrm{mg}$ glucose were added. Lower $H_{\mathrm{f}}$ values were found with the higher concentration of rumen fluid $(1: 2)$ when $6.4 \mathrm{mg}$ glucose were added to the reaction vessel. With all dilutions $H_{\mathrm{f}}$ decreased when the amount of glucose added was increased.

\section{Expt 2}

Table 2 shows the effect of the duration of glucose infusion on stimulated $\dot{H}$ and on $H_{\mathrm{f}}$. The mean preinfusion $\dot{H}$ of eighteen samples ( $15 \mathrm{ml}$ rumen fluid plus $45 \mathrm{ml}$ buffer) was 0.4 (SE 0.02$) \mathrm{mW} / \mathrm{ml}$ rumen fluid. Increasing the duration of glucose infusion $(1.6 \mathrm{mg} / \mathrm{min}$ ) from 1 to $4 \mathrm{~min}$ was associated with a sustained $\dot{H}$. However, an increase in amount of substrate was followed by a significant decrease in $H_{\mathrm{f}}$ from 111 to $86 \mathrm{~kJ} / \mathrm{mol}(P<0.001)$. When a constant amount of glucose was added over different periods of time, e.g. $3 \cdot 2 \mathrm{mg}$ over 1 , 2 or 4 min, similar $H_{\mathrm{f}}$ were obtained (not shown).

\section{Expt 3}

Fig. 2 depicts a single dose-response effect of infusion of 0.4 to $6.4 \mathrm{mg}$ glucose for $1 \mathrm{~min}$ on stimulated $\dot{H}$ on rumen fluid. Basal $\dot{H}$ was 0.36 (SE 0.01 ) $\mathrm{mW} / \mathrm{ml}$ rumen fluid $(n 120)$. The rate and duration of the stimulated $\dot{H}$ were dose-dependent. As shown in Fig. 2, at the highest glucose dose maximal $\dot{H}$ was $1 \cdot 1 \mathrm{~mW} / \mathrm{ml}$ rumen fluid. This $\dot{H}$ level was maintained for 3-5 $\mathrm{min}$. 


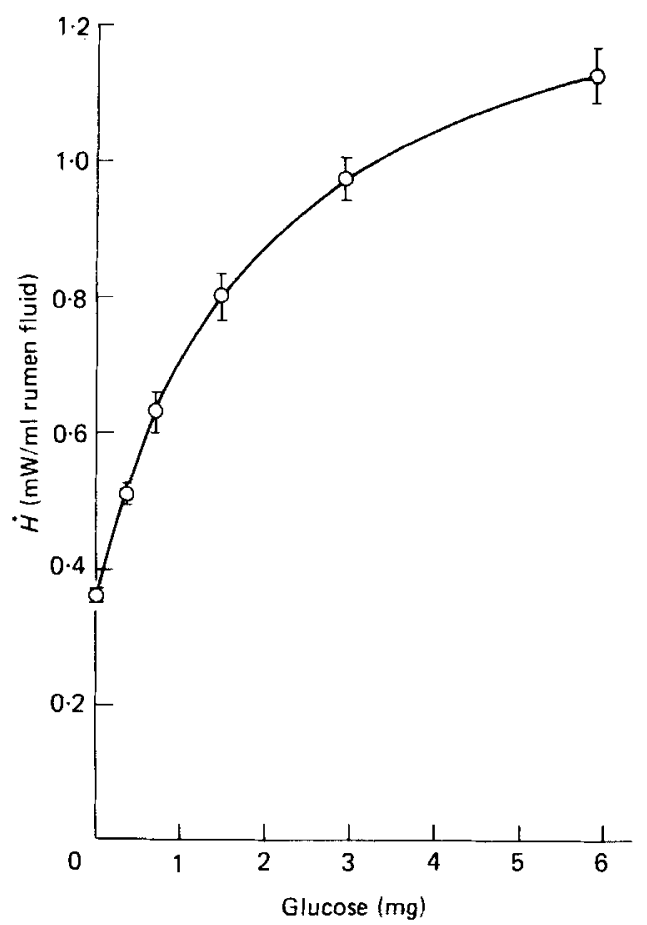

Fig. 2. Expt 3. Effect of glucose on heat production rate $(\mathrm{mW} / \mathrm{ml} ; \dot{H})$ in rumen fluid. Points are mean values with their standard errors represented by vertical bars ( $n 120$ for incubation without glucose, twenty-four replicates for incubations in the presence of glucose).

Table 3 summarizes $H_{\mathrm{f}}$ values obtained from different doses of glucose in the treated samples. A sixteenfold increase in glucose dose was accompanied by an eightfold increase in $H_{\mathrm{f}}$. Hence an increase in glucose dose from 0.4 to $6.4 \mathrm{mg}$ per sample resulted in a decrease of $H_{\mathrm{f}}$ from 149 to $71 \mathrm{~kJ} / \mathrm{mol}(P<0.001)$.

The response relation for $H_{\mathrm{f}} v$. glucose dose could be described by the equation:

$$
y=69 \cdot 2+107 \cdot 4 \mathrm{e}^{-0 \cdot 667 x}
$$

where $y$ is $H_{\mathrm{f}}(\mathrm{kJ} / \mathrm{mol})$ and $x$ is glucose dose $(\mathrm{mg})$.

The correlation coefficient between observed mean values and the values calculated by this equation was $0.9996(n 5, P<0.001)$.

\section{DISCUSSION}

There is little information on the heat evolved during fermentation of available carbohydrates in the rumen (Walker \& Forrest, 1964). Principles of stoichiometry provide a framework for calculating the amount of substrate energy dissipated as heat when a certain amount of substrate is completely fermented. However, when substrate is added to rumen fluid a variable amount of its energy is not fermented but is incorporated into bacterial cells (Ørskov, 1975).

The basal rate of $\dot{H}$ in the present study was constant throughout the incubation period of 2-9 $\mathrm{h}$. Therefore, it is possible that the population of micro-organisms within the samples remained constant. Hence basal $\dot{H}$ may represent the basal energy expenditure for non-growth functions of rumen micro-organisms such as ion balance, protein turnover, etc. (Russell \& Hespell, 1981). 
Table 3. Expt 3. Effect of glucose on heat production in rumen fluid samples

(Mean values with their standard errors for twenty-four determinations)

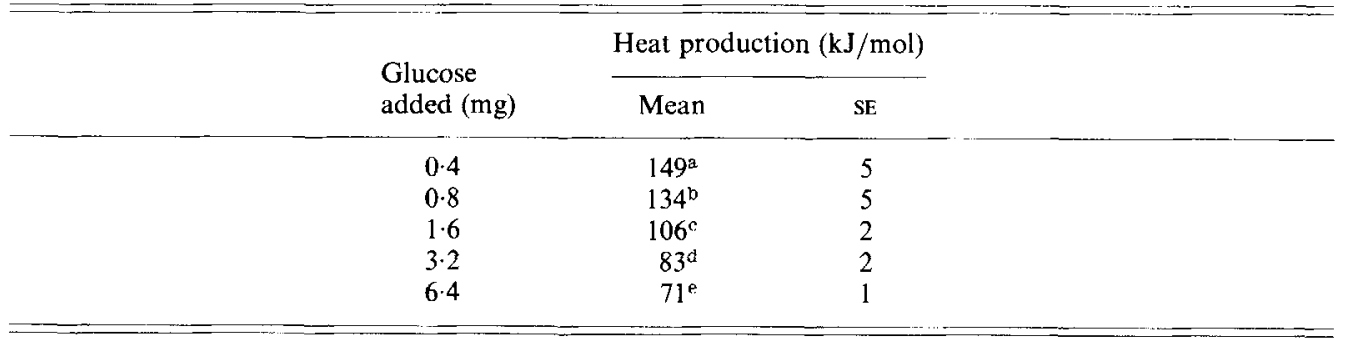

a, b, c. d, e Mean values with different superscript letters differed significantly $(P<0 \cdot 05)$.

The $\dot{H}$ values obtained in the present study were higher than those reported for unbuffered rumen fluid samples from fasting ruminants $(0.07 \mathrm{~mW} / \mathrm{ml}$ and $0.12 \mathrm{~mW} / \mathrm{g}$; Walker \& Forrest, 1964; Houpt, 1968). The finding that the rate of basal $\dot{H}$ in rumen fluid is decreased with increasing concentration of rumen fluid in the medium (Table 1) suggests uptake of substrate from the rumen fluid by the micro-organisms, as substrate flux to micro-organisms is inversely related to population density (El-Shazly \& Hungate, 1965; Button, 1985), whereas the rate of $\dot{H}$ is proportional to cell concentration when endogenous energy sources are used (Nunomura \& Fujita, 1981).

In the present study, the effect of glucose was rapid and of short duration: $\dot{H}$ values returned to basal levels 3-5 min after the introduction of substrate. No measurements of disappearance of glucose and formation of VFA were made. Such measurements would be difficult over the short intervals of time used. However, when a second glucose dose $(1.6$ or $6.4 \mathrm{mg}$ ) was added, $\dot{H}$ increased to levels similar to those obtained after the first dose, suggesting that the return of $\dot{H}$ to basal level was due to the exhaustion of substrate in the medium. This conclusion is compatible with the rate of glucose metabolism in rumen contents, which has a turnover time of $2.5 \mathrm{~min}$ (Hungate, 1966).

The maximal $\dot{H}$ of rumen samples in the present study, $1.1 \mathrm{~mW} / \mathrm{ml}$ rumen fluid, was similar to $\dot{H}$ in rumen fluid samples taken from animals fed on concentrates (Houpt, 1968).

Glucose-induced $\dot{H}$ was related to glucose dose (Fig. 2) but was unaffected by the duration of infusion (Table 2). This may be due to the effect of the initial substrate concentration on $\dot{H}$. The initial glucose concentration in the present study was within the physiological range. Low glucose concentrations (e.g. $0.4 \mathrm{mmol} / \mathrm{l}$ ) are found in animals fed on a mixed roughage - concentrate diet (Takahashi \& Nakamura, 1969), whereas a short time after giving a concentrate diet, glucose concentrations as high as $9.3 \mathrm{mmol} / 1$ rumen content were reported (Mackie et al. 1984).

In the earlier studies, $\dot{H}$ was obtained over fermentation periods of several hours. As the microbial population of the rumen grows at the rate of $8 \% / \mathrm{h}$ (El-Shazly \& Hungate, 1965), it may be presumed that only limited changes occurred in the size of microbial population during the fermentation of glucose in the present study. Hence, the $\dot{H}$ values obtained probably represent direct fermentation of substrates unbiased by variation in population size, which may occur over long fermentation periods.

The main finding of the present study is that under in vitro conditions, direct $H_{\mathrm{f}}$ of glucose by rumen micro-organisms is related to the amount of added substrate. An increase in glucose dose by varying the infusion time (Table 2) or the amount of glucose added (Table 3) resulted in a decrease in $H_{\mathrm{f}}$. It is possible that in the presence of large amounts of glucose, maintenance requirements of the rumen microbes are met and a shift from catabolic to 
anabolic processes is likely, resulting in intracellular accumulation of substrates or synthesis of storage polysacarides (Walker \& Monk, 1971).

The fitted extrapolation equation relating $H_{\mathrm{f}}$ to glucose dose (eqn (1)) predicts that at very small amounts of glucose, about $177 \mathrm{~kJ} / \mathrm{mol}$ substrate energy, could be converted into heat; this is close to the value obtained from stoichiometric calculations (Hungate, 1966). This is probably true when apparently all the substrate is catabolized. On the other hand, in the presence of a large glucose dose (e.g. $6.4 \mathrm{mg}$ glucose/sample), $H_{\mathrm{f}}$ decreased to $70 \mathrm{~kJ} / \mathrm{mol}$ substrate energy.

It is noteworthy that $H_{\mathrm{f}}$ of about $117 \mathrm{~kJ} / \mathrm{mol}$ cellobiose was found when a very large amount ( 2 mmol) was added to rumen contents (Forrest, 1969). In that study $\dot{H}$ in rumen contents was stochiometrically related to VFA production in the reaction mixture.

The results presented in Table 3 are compatible with the hypothesis that an increase in glucose input to rumen micro-organisms is associated with a decrease in the proportion of substrate energy converted to heat. Assuming that $177 \mathrm{~kJ} / \mathrm{mol}$ glucose is dissipated as heat when the substrate is completely fermented (eqn (1)), then with high glucose availability about $60 \%$ of substrate may escape catabolism.

The apparent storage efficiency of available carbohydrates suggested by the present findings and by the results of Forrest (1969) appears to be higher than the average values reported in the literature (Isaacson et al. 1975). This difference might be related to the short-term fermentation, in which efficiency determination does not include deterioration and lysis of cells as compared with the reported efficiency determination. Nevertheless, such calculations are within the percentage range of fermentable organic matter entering cells in the rumen (Leng, 1983). Further studies are, however, required to clarify the conditions influencing the distribution of substrate energy between cells and fermentation.

The author thanks Mr U. Aharoni for use of the exponential iteration program. The financial assistance of the Peter Haas Foundation is gratefully acknowledged.

\section{REFERENCES}

Bauchop, T. \& Elsden, S. R. (1960). Journal of General Microbiology 23, 457-470.

Button, D. K. (1985). Microbiological Reviews 49, 270-297.

El-Shazly, K. \& Hungate, R. E. (1965). Applied Microbiology 13, 62-69.

Forrest, W. W. (1969). In Biochemical Microcalorimetry, pp. 165-180. [H. D. Brown, editor]. New York: Academic Press.

Hershberger, T. V. \& Harstook, E. (1970). Journal of Animal Science 30, 257-261.

Houpt, T. R. (1968). American Journal of Veterinary Research 29, 411-419.

Hungate, R. E. (1966). The Rumen and its Microbes. New York: Academic Press.

Isaacson, H. R., Hinds, F. C., Bryant, M. P. \& Owens, F. N. (1975). Journal of Dairy Science 58, $1645-1659$.

Leng, R. A. (1983). Maximum Livestock Production from Minimum Land, Proceeding of the 3rd Seminar, pp. 79-104. Joydebpur: Bangladesh Agriculture Research Institute.

McDougall, E. I. (1948). Biochemical Journal 43, 99-109.

Mackie, R. I., Gilchrist, F. M. C. \& Heath, S. (1984). Journal of Agricultural Science 103, 37-51.

Marston, H. R. (1948). Biochemical Journal 42, 564-574.

Menke, K. H. \& Ehresvard, U. (1974). In Energy Metabolism of Farm Animals, pp. $91-94$ [K. H. Menke, H. J. Lantzch and J. R. Reichl, editors]. Stuttgart: Hohenheim University Press.

Nunomura, K. \& Fujita, T. (1981). Journal of General Applied Microbiology 27, 357-364.

Ørskov, E. R. (1975). World Review of Nutrition and Dietetics 22, 152-182.

Russell, J. B. \& Hespell, R. B. (1981). Journal of Dairy Science 64, 1153-1169.

Seeley, R. C., Armstrong, D. G. \& MacRae, J. C. (1969). In Energy Metabolism of Farm Animals. pp. 93-100 [K. L. Blaxter, J. Kielanowski and G. Thorbek editors]. Newcastle upon Tyne: Oriel Press.

Takahashi, R. \& Nakamura, K. (1969). Agriculture, Biology and Chemistry 33, 619-621.

Walker, D. J. \& Forrest, W. W. (1964). Australian Journal of Agricultrual Research 15, 299-315.

Walker, D. J. \& Monk, P. R. (1971). Applied Microbiology 22, 741-747.

Webster, A. J. F., Osuji, P. P., White, F. \& Ingram, J. F. (1975). British Journal of Nutrition 34, $125-139$. 